\title{
Adaptation of the proposed unit system for third year architectural design studio
}

\author{
Eray Bozkurt ${ }^{1,}$ \\ ${ }^{1}$ Assist.Prof.Dr., Izmir Yasar University, Department of Architecture, Selcuk Yasar Campus, \\ Bornova, Izmir -35310 Turkey
}

\begin{abstract}
Architectural design studios aim to teach students the fundamental design thinking. Well-structured studio may help the students to explore the global responses and develop projects focused on the current conditions of the society. This study focuses on the adaptation of the proposed unit system for third year architectural design studio. The adaptation process of the proposed unit system analyzed with the description of the previous system. This study discusses the positive outcomes of the new proposed unit teaching method at School of Architecture, Yasar University.
\end{abstract}

\section{Introduction}

Architectural studio is the main core of education for design based architectural schools. These architectural design studios are continuously exploring many learning environments. They have studio coordinators that provide organized working environment. It is hard to define the correct path to follow, however studio coordinators' attempts can provide new opportunities that will tackle the current needs of the constantly changing challenges in architectural design education.

Architectural design education has remained the same for many centuries [1], however there is a growing dissatisfaction appears to be the main concern of researchers and academicians around the world. In the study environment of architectural studio, design tutors play an important role to educate the registered university students. The minimum requirement expected from design tutors is their previous practice experiences. However, the academic requirements are more tough compared to their practice careers. The expected level of academic career involves being expert on a particular architectural subject, and good pedagogical mentality to teach architecture students. The quality of the tutors can increase the flexibility potential of the studio's main frame. If any modification occurs in the studio teaching system, they have many years of experiences to adapt themselves to new conditions. Students' reactions are more important at this stage. They can suffer from the unexpected changes in the studio environment.

\footnotetext{
* Corresponding author: eray.bozkurt@,yasar.edu.tr
} 
The current study was structured in Yaşar University's school of architecture in Izmir. The observation evaluated the students who attended third year studio in Spring 2018. They were the first group of students who experienced the proposed unit system teaching.

Conventional studio system given before Spring 2018 semester, focused on one particular type of design project. The brief was about the design of an education facilities in a given location. This approach was questioned in many occasions as placing studio away from the current debates in architectural education and society. The expectations of society is rapidly changing in many directions. The proposed unit system teaching has emerged to resolve the problems about how to adapt the studio environment to rapid changes in building industry and society. The proposed unit system provides variety of interesting subjects to choose from and give more freedom for the students to explore their abilities in a desired working environment.

\section{Adapting the architectural education to current debates}

It's not wrong to claim that sustainable, energy conscious and environmentally responsive design approaches have been contributing to reduce the carbon emissions. The sustainable design approaches have been in action since 1970s oil crisis, contributed in many occasions to lower the carbon emissions. It's needless to say that sustainable, environment and energy topics will be valid for the next generations. Any architectural school should develop curriculum that considers sustainable strategies, climate change, energy efficiency, waste management, resource deflation etc.

Generally architectural education consists of two parts. The first part is the studio-based design education where students explore their design projects and implement practical solutions with their theoretical background. The second part is the theoretical part, which improves the students' knowledge about the architectural discipline. The flexibility of the architectural studio environments can help to adjust to study the current debates in international society.

\section{Architectural studio education}

Architectural schools are organizations that are frequently quite stable in the short term, but inevitably evolving over the longer term in response to changes in conditions. Many architectural schools have launched programs aiming to imply changes in the theoretical lessons and design studios. There are various debates for changing non-renewable with more renewable and efficient teaching methods. The conventional teaching and learning approaches may not be appropriate for addressing the current undergraduate education.

The discussions on the curriculum changes is always valid in Turkey because of country's dynamic nature. Any new developments can find response from communities; however it can fade away very quickly to open a newer development. Architectural education is also in constant change due to the expectations of communities. Students before they enter the university, don't have right and sufficient skills to complete the undergraduate curriculum. Universities' architecture schools facing this problem, spend most of their tutors' time and resources to train students to tackle undergraduate curriculum. Another part of the problem is, students who will attend third year design studio, entered the university with the Turkish national exam. They needed to collect enough scores to be successful candidates. They had sufficient skills in science and math subjects, however the exam system does not provide valuable information about their art and entrepreneur skills. After entering the university, these skills were triggered by the firstyear design tutors. When students reached to their third-year level, they were all ready to 
work on full program architectural design projects. This effects the universities main targets, leaving less time for research activities till their graduations.

The proposed unit system aims to trigger research capacity of the students and help them to experience more innovative design solutions. This way, more time will be given to the research related study environment. That improves the education quality of architectural schools.

\subsection{Conventional studio description}

Conventional architectural studio is influenced from Bauhaus traditions and pick adaptations on the way. Architectural schools may change the original structure depending on the geographical location and their communities' expectations. Before Spring 2018, architecture school at Yasar University structured its third year conventional architectural studio with the strategy on a design program dedicated to one particular building type; education facility. The brief asked students to design a school project for a given location. The minimum requirements were the spatial sizes and their functions provided to the students. Students distributed among the design tutors randomly and were reviewed by at most two tutors till the end. During the design period, students may focus more on representation and improvements of their proposed education facility rather than showing efforts on the new design and construction developments. This approach weakened the strength of their projects innovative nature. During the assessment period, the external examiners gave comments to students' projects without grading them. The group tutors gave their own decisions with or without considering the contributions of external examiners. The projects' performances were under the control of the groups' design tutors. This leads the speculation about the tutors' attitude. At some stages of the projects, it's claimed by some students that the design tutors' personal interests helped students to develop their ideas.

\subsection{Proposed unit system}

The aim of the study is to analyse the adaptation of the unit system strategy in third year architectural studio in Izmir Yasar University. The university's physical environment is not sufficient to support atelier system, existing spaces are shared by different departments. The atelier system needs studio spaces for each design topic that can be used by only by architecture students, twenty-four hours in a day and seven days a week. The third-year coordinator checked the physical conditions and decided not to proceed on the atelier system. Instead of the atelier system, the students were divided into four parts, represented as unit. These four units explored the current trends in the architecture field. The course coordinator organized the fourteen weeks of the studio period, depending on the submission requirements. Each unit had two instructors with similar academic subjects. They controlled their units' learning environment and helped students to explore various design thinking. The course coordinator organized the assessment process and the correlations between the units according the given targets. The site visit was conducted at the beginning of the semester. Before the site visit, the students researched the area. Later, they combined their knowledge with on-site investigations. The students formed a group of three, in the end there were 56 groups in total. The design programs for each group were emerged from their researches on their interests and site investigation reports. In the semester plan, the students experimented ideas on the design concept, structure, environmental control systems, materials, and presentation techniques. Each unit was assessed by its two-unit instructors. During the major assessment periods like open juries, other unit instructor and an external examiner joined to the unit team. The course coordinator assigned external 
examiner from the professional practice who had various expertise on the construction and design of influential buildings. This approach helped students to interact with the professional people in the architecture field. Four jury members at the end, formed an assessment panel with equal amount of grading percentage. As a result, students made less complaints about their tutors being not fair to them.

\subsection{Discussion}

Design teaching is given in the architectural design studios planned in a one semester or yearly. The whole education weeks in a semester period, planned to organise the students to trigger different approaches of design solutions. The conventional method brought limitations and constraints on the design program possibilities. The conventional method expected students to concentrate over the guidelines given by the instructors more strictly. The new teaching approach has triggered the creativity of design thinking process. The students explored the different perspectives of the design approaches and dedicated more on their researches.

The students' creative thinking process were observed to measure the opportunities of the new method. In all cases, the development of the design thinking process is key to any similar studies.

\section{Conclusion}

Architecture field is an extremely complex professional that it's hard to predict where architects' role will be useful on different types and scaled projects. One day it's possible for an architect to design a concert hall or next year, will put all the efforts on climate research center project. The quality of the university education at that level comes to discussion. If one to describe a successful architecture school, definitely is a place that provides the necessary skills and research abilities for its graduates. Architecture school that influences future architects to work in harmony with other professionals, can make their graduates more competent in international society. Architectural design studio environment is a valuable asset for school of architectures to increase the quality of their curriculums. However, they need more interdisciplinary connections and researches to handle the sustainability in building industry. However, the real problem is to adapt a suitable teaching method to challenge current trends.

It's crystal clear that architectural studios must adapt sustainable topics into their learning environment. Many experts claimed that sustainability is the only model for the next generation.

\section{References}

1. Bashier, F. Reflections on architectural design education: The return of rationalism in the studio. Front. Archit. Res. 3, 424-430 (2014).

2. Haase, J. Changing Trends in Architectural Design Education. in The International Conference of the Center for the Study of architecture in the Arab Region 520-534 (2006).

3. Lueth, P. L. O. The architectural design studio as a learning environment: A qualitative exploration of architecture design student learning experiences in design studios from first- through fourth-year. 238 (2008). doi:10.1017/CBO9781107415324.004.

4. Riley, S. et al. Designing the future - are our university staff up to it? 9th International 
Conference on Engineering \& Product Design Education: Shaping the Future? 361366 (2007).

5. Aydemir, Z. Connotations in Architectural Design Education. in Contemporary Discussions and Design Methodologies in Architecture ARCHDESIGN '14 / Architectural Design Conference Proceedings 91-100 (2014).

6. Gerards, S., Bleeckere, S. De \& (Hasselt University, Hasselt, B. Narrative Thinking in Architectural Education. in ARCC/EAAE 2014 | Beyond Architecture: New Intersections \& Connections Methods: Agents of Change in Changing Paradigms. Scientifi c, Technological, Strategic, Intuitive, and Pragmatic. 305-311 (2005).

7. Cheng, R. Designers designing design education. J. Archit. Educ. 68, 12-14 (2014).

8. Kahvecioğlu, N. P. Architectural design studio organization and creativity. A|Z ITU J. Fac. Archit. 4, 6-26 (2007).

9. Savage, K. \& O'Brien, M. Architectural education-studio based learning. DS 38 Proc. E DPE 2006, 8th Int. Conf. Eng. Prod. Des. Educ. 87-94 (2006).

10. Ascher, B. E. The bauhaus: Case study experiments in education. Archit. Des. 85, 3033 (2015).

11. Ibrahim, N. L. N. \& Utaberta, N. Learning in Architecture Design Studio. Procedia Soc. Behav. Sci. 60, 30-35 (2012).

12. Seelig, M. \& Seelig, J. Architectural education: On flies, bees, and the architectural studio. Archit. Rec. 173, 51-55 (1985).

13. Mathew, L. Future Directions in Architectural Design Education-Parametric Modeling. QRS Repos. 13 (2011). doi:10.5339/qnrs.2011.13 